\title{
Correlation of Thrombolytic and Membrane Stabilizing Activities with Total Flavonoid Content Aerial Parts of Spondias pinnata
}

\author{
Jalal Uddin', Md. Nurul Islam³ ${ }^{3}$ Md. Haider Ali ${ }^{1}$, Shah Alam Khan² \\ and Zubair Khalid Labu ${ }^{1}$ \\ ${ }^{1}$ Department of Pharmacy, World University of Bangladesh, Dhaka-1205, Bangladesh \\ ${ }^{2}$ Department of Pharmacy, Oman Medical College, Muscat, Sultanate of Oman \\ ${ }^{3}$ Amico Laboratories Ltd., Dhaka, Bangladesh
}

Received: August 10, 2015; Accepted: December 20, 2015; Published (Web): February 17, 2016

\begin{abstract}
Spondias pinnata is a medicinal herb belonging to the family of Anacardiaceae. Locally it is known as Amra and has a history of ethno-medicinal properties. The crude ethanolic extract along with different partitionates of the leaves of $S$. pinnata were evaluated for their possible thrombolytic and membrane stabilizing activities. The activities of the leaf extract were evaluated by using standard drugs; streptokinase for thrombolytic and acetyl salicylic acid for anti-inflammatory activities. In this study, among all partitionates the ethyl acetate soluble fraction showed highest \% of clot lysis (58.06\%) as compared to (69.23\%) and (3.03\%) exhibited by the standard streptokinase and water. On the other hand, ethyl acetate soluble fractionates also significantly inhibits the haemolysis of human erythrocyte membrane both in induced by hypotonic solution $(65.33 \pm$ $0.50 \%)$ and by heat $(56.22 \pm 0.69 \%)$, respectively as compared to $(75.92 \pm 29 \%)$ and $(71.12 \pm 0.26 \%)$ demonstrated by acetyl salicylic acid. Our study revealed that satisfactory amount of flavonoid content $(132.27 \pm 0.25)$ showed a significant and positive correlation between total flavonoid content with thrombolytic and membrane stabilizing activities.
\end{abstract}

Key words: Spondias pinnata, thrombolytic activity, membrane stabilizing activity, flavonoid content

\section{Introduction}

Medicinal plants are one of the important contributors to the most of the medicinal preparations as raw plant materials, refined crude extracts and mixtures. Several thousands of plants have been known to possess medicinal values and are used to treat different ailments in various cultures worldwide (Farnsworth, 1991). S. pinnata (Family-Anacardiaceae) is widely used as a medicinal plant in Bangladesh. Generally it is known as wild mango, hog-plum and available in the forests of Chittagong, Chittagong Hill Tract, Cox's Bazar, Dhaka, Tangail, Sylhet and Dinajpur (Ethnobotanybd, 2010). It has been reported that aerial parts of this plant contain various phytochemicals such as 24-methylene cycloartenone, stigmast-4-en-3-one, $\beta$-sitosterol, glycoside of $\beta$ sitosterol and lignoceric acid. Fruits contain water- soluble polysaccharides, composed of mainly Larabinose, D-galactose and galacturonic acid. $\beta$-amyrin, oleanolic acid, glycine, cystine, serine, alanine and leucine have also been detected in the fruits of this plant. It is useful in dysentery, diarrhea, stomachache, rheumatism, and swollen joints and is also given to prevent vomiting (Hazra et al., 2008). A paste of it is used as an embrocation for both articular and muscular rheumatism. A decoction of the bark is given in gonorrhea. The root of the plant is considered to be useful in regulating menstruation. It has also excellent antioxidant and anti-tubercular properties. The unripe fruit is good for rheumatism and sore throat. The Ayurvedic pharmacopeia of India also recommends the use of stem bark in hemorrhagic disease. Wetwitayaklung et al., 2012 reported that young shoot are eaten as vegetable, fruits are used as vitamin $\mathrm{C}$

Correspondence to: Zubair Khalid Labu; Cell: 01558388956; E-mail: zubair.labu@yahoo.com 
supplement and anti-thirst, and bark is used as antivomit and diuretic (Ghani 2003). Finally, the research activities have been focused on the phytochemical investigation of the plants which have ethno-botanical and folkloric importance associated with them for drug discovery (Daginawala et al., 2006). Because of its copious, widespread availability and folkloric use and presence of significant amount of flavonoid, the present study was undertaken to investigate the potential of Spondias pinnata leaves extract as membrane stabilizing and thrombolytic agent (Giuseppina et al., 2010).

\section{Materials and Methods}

Plant materials: The plant, S. pinnata was collected from the National Botanical Garden, Dhaka, Bangladesh in August, 2014 and was identified by the taxonomist of Bangladesh National Herbarium, Mirpur, Dhaka. Voucher specimens (DACB accession no. 36703) for this plant have been maintained in Bangladesh National Herbarium for future reference.
Preparation of extract: The collected plant leaves were shade dried for several days and then oven dried for 24 hours at $40{ }^{\circ} \mathrm{C}$ to facilitate grinding. The powdered leaves were then stored in a tight container. The dried powder material (400 gm) was soaked in $1000 \mathrm{ml}$ of $90 \%$ ethanol for two weeks and was shaken occasionally. The whole mixture was filtered by a piece of clean, white cotton followed by Whatman filter paper. The filtrate was dried using a vacuum rotary evaporator at optimum temperature of $40{ }^{\circ} \mathrm{C}$ to obtain the crude extract of $S$. pinnata. The concentrated aqueous ethanol extract was partitioned by the Kupchan method and the resultant partitionates, i.e. ethyl acetate, chloroform, $n$-hexane and aqueous soluble materials were used for the current investigation.

Phytochemical screening: The freshly prepared organic extracts were qualitatively tested for the presence of various classes of Phytochemicals. These were identified by characteristic color changes using standard procedures (Sofowara, 1993) and are presented in (Table 1).

Table 1. Results of phytochemical screening of different partitionates of $S$. pinnata leaves.

\begin{tabular}{lccc}
\hline Test for & HXSF & CSF & ESF \\
\hline Carbohydrates & - & + & + \\
Reducing sugar & - & + & + \\
Steroid & + & - & - \\
Alkaloids & + & + & + \\
Flavonoids & + & + & + \\
Tannins & + & + & + \\
\hline
\end{tabular}

+ indicate present; - Indicate absent.

Determination of total flavonoid content: The total flavonoid content was estimated using previously described which is based on determination of the flavonoid-aluminum complex between flavonoid of the crude extract and aluminum chloride (Chang et al., 2002).

The total flavonoids contents of leaves of $S$. pinnata were calculated using the standard curve of quercetin $\left(\mathrm{y}=0.0098 \mathrm{x}-0.0364 ; \mathrm{R}^{2}=0.9724\right)$ and expressed as quercetin equivalents (QAE) per gram of the plant extract.
In vitro thrombolytic activity: The thrombolytic activities of prepared extracts were evaluated as the method described previously (Daginawala, 2006) using streptokinase (SK) as positive and water as negative controls. The tubes containing pre-weighed clot was properly labeled, $100 \mu \mathrm{l}$ crude extract and aqueous solutions of different fractionates were added to the tubes separately. As a positive control, $100 \mu \mathrm{l}$ of SK and as a negative non thrombolytic control, $100 \mu \mathrm{l}$ of isotonic solution was separately added to the clot containing tubes. All the tubes were then incubated at $37{ }^{\circ} \mathrm{C}$ for 90 minutes and observed for clot lysis. After 
incubation, the released fluid was removed and vials were again weighed to observe the difference in weight after clot disruption. The percentage of clot lysis was calculated by using the following equation:

$\%$ of clot lysis $=($ wt. of released clot /clot wt. $) \times 100$.

Statistical analysis: All the assays were done in three replicates of each sample and values were taken as mean \pm SD by statistical analysis.

In vitro membrane stabilizing assay: The hypotonic and heat induced membrane stabilizing activity of the extractives were determined on human erythrocytes by the method of Omale (Omale et al., 2008).

\section{Results and Discussion}

Total flavonoid content: Total flavonoid contents of various fractions of S. pinnata leaves extracts were expressed as $\mathrm{mg}$ of quercetin equivalents/gm of dried extract (Table 2).

Table 2. Total flavonoids contents of the ethanolic extracts of different partitionates of $S$. pinnata.

\begin{tabular}{lc}
\hline $\begin{array}{l}\text { Different fractionates } \\
\text { of leave extract }\end{array}$ & $\begin{array}{r}\text { Total flavonoids content (mg of } \\
\text { QAE /gm of plant extract) }\end{array}$ \\
\hline ESF & $132.27 \pm 0.25^{\mathrm{a}}$ \\
HXSF & $47.37 \pm 0.47^{\mathrm{b}}$ \\
CSF & $60.76 \pm 1.80^{\mathrm{b}}$ \\
\hline
\end{tabular}

Results are expressed as mean $\pm \mathrm{SD}(\mathrm{n}=3)$, values in the same column followed by different letter $\left({ }^{\mathrm{a}, \mathrm{b}}\right)$ are statistically significant $\left({ }^{\mathrm{a}} \mathrm{P}<0.05\right)$.

Since, all the fractions exhibited positive results for flavonoid in the preliminary phytochemical screening; the same is quantified by the analysis of total flavonoid content. However, ethyl soluble fraction exhibited the highest flavonoid content $(132.27 \pm 0.25 \mathrm{mg} / \mathrm{gm})$ while hexane soluble fraction was found to contain the lowest flavonoid content $(47.37 \pm 0.47 \mathrm{mg} / \mathrm{g})$.

Thrombolytic activity: From in vitro thrombolytic activity study revealed that addition of $100 \mu \mathrm{l}$ streptokinase (SK) for fibrinolytic drugs as a positive control (30,000 IU) to the clots and subsequent incubation for 90 minutes at $37{ }^{\circ} \mathrm{C}$ showed $69.23 \%$ lysis of clot on the other hand sterile distilled water a, negative control exhibited a negligible percentage of lysis of clot 3.03\%, ethanolic extract (EE) $43.28 \%$, ethyl acetate soluble fraction (ESF) $58.06 \%$, chloroform extract (CSF) $27.66 \%$ and aqueous soluble fraction (AQSF) $22.81 \%$ showed lysis of clot respectively. In this study, it was observed that the ethyl acetate soluble fraction of $S$. pinnata showed highest thrombolytic activity. Hence the obtained results were compared with the control groups, where values of $* * \mathrm{P}<0.001$, considered statistically significant (Table 3 ).

Membrane stabilizing activity: From in vitro membrane stabilizing activities revealed that, at 2 $\mathrm{mg} / \mathrm{ml}$, different partitionates of crude extracts of $S$. pinnata significantly protected the haemolysis of HRBC membrane induced by hypnotic solution and heat as compared to the standard ASA. Therefore, by hypnotic solution, values of ASA (75.92 $\pm 0.29 \%)$, AQSF $(33.49 \% \pm 0.51), \operatorname{HXSF}(52.33 \% \pm 0.64)$, CSF $(49.66 \pm 0.77)$ and ESF $(65.33 \pm 0.50 \%)$, respectively while in heat with the values ASA $(71.12 \pm 0.26)$, AQSF $(30.34 \% \pm 0.42), \operatorname{HXSF}(49.33 \% \pm 0.6), \mathrm{CSF}$ $(46.22 \pm 0.57 \%)$, ESF $(56.22 \pm 0.69 \%)$, respectively (Table 4).

Table 3. Thrombolytic activity of different fractionates crude extract of S. pinnata.

\begin{tabular}{lcccccc}
\hline Fractions & $\begin{array}{c}\text { Weight of empty } \\
\text { vial (A) g }\end{array}$ & $\begin{array}{c}\text { Weight of vial with } \\
\text { clot (B) g }\end{array}$ & $\begin{array}{c}\text { Weight of } \\
\text { clot (B-A)g }\end{array}$ & $\begin{array}{c}\text { Weight of vial with } \\
\text { clot after lysis (D) g }\end{array}$ & $\begin{array}{c}\text { Weight of clot } \\
\text { lysis (B-D)g }\end{array}$ & $\begin{array}{c}\text { \%of clot } \\
\text { lysis }\end{array}$ \\
\hline HXSF & 5.14 & 5.91 & 0.67 & 5.62 & 0.29 & $43.28^{*}$ \\
ESF & 5.29 & 6.22 & 0.93 & 5.68 & 0.54 & $58.06^{* *}$ \\
CSF & 5.28 & 5.75 & 0.47 & 5.62 & 0.13 & $27.66^{*}$ \\
SK & 4.65 & 5.04 & 0.39 & 4.77 & 0.27 & $69.23^{* *}$ \\
Blank & 5.20 & 5.53 & 0.33 & 5.52 & 0.01 & $3.03^{*}$ \\
\hline
\end{tabular}

$* \mathrm{P}<0.005, * * \mathrm{P}<0.001$; statistically significant as compared to positive control and negative control. 
Table 4. Percentage $(\%)$ inhibition of heat and hypotonic solution induced haemolysis of erythrocyte membrane by standard and different fractions of $S$. pinnata.

\begin{tabular}{lcc}
\hline Samples & \multicolumn{2}{c}{$\%$ Inhibition of haemolysis } \\
\cline { 2 - 3 } & Heat induced & Hypotonic solution induced \\
\hline Hypotonic medium & - & - \\
HXSF & $49.33 \pm 0.61$ & $52.33 \pm 0.64^{*}$ \\
ESF & $56.22 \pm 0.69^{*}$ & $65.33 \pm 0.50^{* *}$ \\
CSF & $46.22 \pm 0.57$ & $49.66 \pm 0.77^{*}$ \\
AQSF & $30.34 \pm 0.42$ & $33.49 \pm 0.51^{*}$ \\
ASA & $71.12 \pm 0.26^{*}$ & $75.92 \pm 0.29^{* *}$ \\
\hline
\end{tabular}

Values are expressed as mean $\pm \mathrm{SD}$ (standard deviation); $* \mathrm{P}<0.005, * * \mathrm{P}<0.001$; statistically significant as compared to ASA. $($ ASA $)=$ acetyl acetic acid

The results of this study showed that, ESF of $S$. pinnata showed $(65.33 \pm 0.35 \%)$ inhibition of hemolysis induced by hypnotic solution and $(56.22 \pm$ $0.69 \%$ ) by heat, respectively and thus leads to protection of haemolysis of HRBC membrane. So from the observed results, it can be proposed that the inhibition of erythrocyte lysis property of $S$. pinnata could be the possible mechanism of action of its antiinflammatory activity.

Correlation of total flavonoid content with thrombolytic and membrane stabilizing activities of $S$. pinnata: For total flavonoid content a significant but marginal positive correlation (value of, $* * \mathrm{P}<0.001 ; * \mathrm{P}$ $<0.005 ;{ }^{a} \mathrm{P}<0.05$ was statistically significant as compared with thrombolytic, membrane stabilizing activities of ethyl soluble fraction) was found. This showed a good relationship between flavonoid content with the thrombolytic, membrane stabilizing activities of S. pinnata.

\section{Conclusion}

The extracts of different polarities of S.pinnata showed significant in vitro thrombolytic and membrane stabilizing activities. It may be assumed that these extracts can be considered as good source of thrombolytic (Basta G et al., 2004) and membrane stabilizing agents due to presence of high amount of flavonoids. However, more detailed phytochemical analysis will be necessary to isolate and characterize the active compounds responsible for the thrombolytic and membrane stabilizing activities as well as to understand the exact mechanisms of action of these activities.

\section{Acknowledgements}

Authors would like to thank National Herbarium of Bangladesh, Mirpur, Dhaka for identifying the plant. Authors also wish to thank the authority of World University of Bangladesh for their financial support to conduct the research.

\section{References}

Basta, G., Lupi, C., Lazzerini, G. and Chiarelli, P.L. 2004. Therapeutic effect of diagnostic ultrasound on enzymatic thrombolysis. An in vitro study on blood of normal subjects and patients with coronary artery disease. Thrombus Haemost. 91, 1078-1080.

Chang, C., Yang, M., Wen, H. and Chern, J. 2002. Estimation of total flavonoid content in propolis by two complementary colorimetric methods. J. Food Drug Analay. 10, 178-182.

Daginawala, H.F., Prasad, S., Kashyap, R.S., Deopujari, J.W., Purothi, H.J. and Taori, G.M. 2006. Development of an in vitro model to study clot lysis activity of thrombolytic drugs. Thrombosis J. 4, 14.

Ethno botanical database of Bangladesh, 2010. The article was retrieved from" http://www.ethnobotanybd.com/ index.

Farnsworth, N.R. and Soejarto, D.D. 1991. Global importance of medicinal plants. Cambridge University Press. pp. 2551.

Ghani, A. 2003. A Medicinal Plants of Bangladesh. The Asiatic Society of Bangladesh, $2^{\text {nd }}$ Revised Ed. 60-63. 
Giuseppina, P., Parpinelloa, F.S. and Daniele, D.R. 2010. Prediction of total antioxidant capacity of red wine by Fourier transform infrared spectroscopy. Journal homepage: www.elsevier.com/locate/foodcont Food Control 21 786-789

Hazra, B., Biswas, S. and Mandal, N. 2008. Antioxidant and free radical scavenging activity of Spondias pinnata. BMC Complement Altern. Med. 8, 63.

Omale, J. and Okafor, P.N. 2008. Comparative antioxidant capacity, membrane stabilization, polyphenol composition and cytotoxicity of the leaf and stem of Cissus multistriata. Afr. J. Biotechnol. 7, 3129-3133.
Sofowara, A. 1993. Medicinal plants and traditional medicine in Africa. Spectrum Books Ltd., Ibadan, Nigeria. p. 289

Wetwitayaklung, P., Charoenteeraboon, J., Limmatvapirat, C. and Phaechamud, T. 2012. Antioxidant activities of some Thai and exotic fruits cultivated in Thailand. Res. J. Pharm. Biol. Chem. Sci. 3, 12-21 